Research, part of a Special Feature on Exploring Opportunities for Advancing Collaborative Adaptive Management (CAM): Integrating Experience and Practice

\title{
Resilience in Transboundary Water Governance: the Okavango River Basin
}

\author{
$\underline{\text { Olivia O. Green }}^{1}, \underline{\text { Barbara A. Cosens }}^{2}$ and Ahjond S. Garmestani ${ }^{1}$
}

\begin{abstract}
When the availability of a vital resource varies between times of overabundance and extreme scarcity, management regimes must manifest flexibility and authority to adapt while maintaining legitimacy. Unfortunately, the need for adaptability often conflicts with the desire for certainty in legal and regulatory regimes, and laws that fail to account for variability often result in conflict when the inevitable disturbance occurs. Additional keys to resilience are collaboration among physical scientists, political actors, local leaders, and other stakeholders, and, when the commons is shared among sovereign states, collaboration between and among institutions with authority to act at different scales or with respect to different aspects of an ecological system. At the scale of transboundary river basins, where treaties govern water utilization, particular treaty mechanisms can reduce conflict potential by fostering collaboration and accounting for change. One necessary element is a mechanism for coordination and collaboration at the scale of the basin. This could be satisfied by mechanisms ranging from informal networks to the establishment of an international commission to jointly manage water, but a mechanism for collaboration at the basin scale alone does not ensure sound water management. To better guide resource management, study of applied resilience theory has revealed a number of management practices that are integral for adaptive governance. Here, we describe key resilience principles for treaty design and adaptive governance and then apply the principles to a case study of one transboundary basin where the need and willingness to manage collaboratively and iteratively is high — the Okavango River Basin of southwest Africa. This descriptive and applied approach should be particularly instructive for treaty negotiators, transboundary resource managers, and should aid program developers.
\end{abstract}

Key Words: adaptive governance; international water law; Okavango; resilience; transboundary water governance; treaty design

\section{INTRODUCTION}

The interactions among a society, its government agencies, and the ecosystems they manage, create great challenges when dealing with cross-scale issues such as transboundary water governance (Cash et al. 2006, Benson and Garmestani 2011). Law plays a key role in shaping policy and management actions that influence the trajectory of ecosystem health (Garmestani et al. 2009). Given that law is both a driver of and means to implementing environmental policy and governance, legal analysis is essential for understanding policy success and failure, and for developing solutions. Emerging studies reveal that current strict legal regimes are ill-suited for dealing with transboundary resources because they are designed around an outdated conception of socialecological systems (Benson and Garmestani 2011). Environmental and natural resource management laws arose from an engineering perspective geared toward reducing environmental variation, eliminating uncertainty (Anderies 2006), and optimizing for key resource values (Walker and Salt 2006). However, by suppressing natural dynamics, engineered systems may actually be more vulnerable to random disturbance, resulting in an overall reduction of resilience in the system (Anderies 2006, Cosens 2013, Cosens et al. 2012).
The solution to the resilience problem may be adaptive management, initially developed as a methodology for ecosystem management (Holling 1978). Fundamentally, adaptive management attempts to reduce the uncertainty associated with managing ecosystems by continuously learning about the system, in contrast to engineering away uncertainty. Much of the uncertainty in ecosystem management is a result of nonlinear dynamics, and understanding system dynamics is vital to understanding and managing the system. Thus, the most critical steps in adaptive management are the design and implementation of ecosystem monitoring and the iterative process of feeding that information back into management actions (Garmestani et al. 2009). Natural resource management then evolves from a system of strict control to a cycle of experimenting, monitoring, learning, and adapting.

Although it was initially developed by ecologists, adaptive management has gradually incorporated elements from policy and social sciences, resulting in broader application. In addition to direct monitoring data from the ecosystem of interest, adaptive management now integrates information from stakeholders, citizens, and others with local knowledge. Notably, no one-size-fits-all prescription or blueprint for adaptive management exists; rather, the development of 
adaptive management strategies is context and scale dependent. However, there are a few key components which do provide guidance for an adaptive management strategy:

1. Baselines are established and models are used to illuminate potential results of management actions.

2. Monitoring is essential and must be carefully designed to measure components that provide indicators of system health, and to capture components that experience measurable change on a timescale relevant to informing management decisions.

3. Incorporating a variety of knowledge sources into initial and revised management actions is critical.

4. Management actions are revisited in light of new information from system monitoring.

However, the flexibility inherent in this iterative approach is at odds with current approaches to environmental and natural resources law, where certainty is the endgame (Cosens 2012). Natural resource management often faces even greater challenges at the international scale where often a single document, for example, a treaty, controls. During negotiations, admitting uncertainty may weaken the likelihood of agreement, and given the difficulties of reaching agreement in the first instance, adapting treaties to changed circumstances is incredibly difficult. Many treaties have no sunset clause and are surprisingly short on governance details, and many ignore the possibility of circumstances changing (Odom and Wolf 2011). When circumstances change, an older treaty drafted to govern a river that has changed dramatically may still be the law of the land.

Rigidity problems could be overcome through a common negotiation practice, whereby negotiators outsource management details by establishing an international agency to comanage the shared resource. In this instance, we would suggest manifesting an agreement to collaboratively and adaptively manage a shared river basin by establishing a mechanism for international cooperation at the river-basin scale, bound to operate according to adaptive management principles. As long as process is emphasized in the treaty, along with the inclusion of proven treaty mechanisms for enhanced cooperation, co-riparians may overcome the challenges of international resource management, while also fostering social-ecological resilience. Below, we describe key treaty and governance mechanisms as a framework for iterative and cooperative transboundary water management, and then apply this framework in an analysis of the Okavango River Basin and the organization charged with governing it.

\section{TREATY ELEMENTS FOR INSTITUTIONAL AND ECOLOGICAL RESILIENCE}

Conflict among states over shared water resources impedes collaborative management, and treaty design plays an important role in minimizing conflict. Here, institutional resilience is measured by levels of conflict and cooperation in the basin; it reflects the stability of water management regimes and not necessarily the ecological resilience of the watershed (Green and Perrings 2013). The unique socioeconomic and physical characteristics of each international basin preclude strict prototypes for building resilient water management institutions (Ostrom et al. 2007). Thus, each treaty articulates a distinct composition of governance provisions. Some treaties establish management regimes that are iterative, where information is shared and conflicts are avoided. Others plan for extreme events, monitor continuously, and manage jointly. Some treaties include many of these provisions, whereas other treaties address a single issue (e.g., flood control) (Oregon State University 2013). In essence, treaty design, as opposed to the mere presence of a treaty, drives the stability of the institution (Dinar et al. 2010). Although rules for treaty design do not exist, patterns have emerged that illustrate potential relationships among particular provisions, institutional resilience, and adaptive capacity (Dinar et al. 2010, Adger et al. 2011).

Such patterns are the result of a systematic, empirical approach to analyzing treaties and quantifying cooperation conducted through the Transboundary Freshwater Dispute Database (TFDD; Oregon State University 2013). The TFDD collection of over 450 treaties underwent a content analysis for a wide variety of treaty provisions (Hamner and Wolf 1998, Oregon State University 2013). Water-related events were collected as reported in the media and scaled along the Basins at Risk spectrum for the degree of conflict and cooperation (Yoffe et al. 2003). Statistical analysis revealed the significance of particular treaty provisions with respect to conflict among treaty signatories (Dinar et al. 2010). Below, we discuss the treaty elements with the most significant statistical relationship to institutional capacity, as measured by reported state grievances, and those that are most vital to iterative governance.

\section{Water allocation method}

How states physically share water resources is the most conflictive issue between riparian neighbors, yet states rarely delineate water allocations (Giordano and Wolf 2003). Further, the treaties that do specify allocation quantities most commonly do so by fixed volumes, ignoring dynamic hydrology, social values, and human and environmental needs. Rigid entitlements do not account for hydrologic variability; the Intergovernmental Panel on Climate Change predicts such rigidity will lead to increased international tension (McCarthy et al. 2001). As such, flexibility in the method of water allocation is a critical signal of institutional resilience to physical disturbance (Dinar et al. 2010, Odom and Wolf 2011). Statistically, only allocation by percentage of flow, which inherently reflects availability, reduces the intensity of conflict and facilitates collaborative management between riparian 
states. The lack of an allocation mechanism, inclusion of fixed allocations, and the allocation of entire rivers elicit more intense complaints between states (Dinar et al. 2010).

However, it should be noted that allocation by percentage of flow, although positive for institutional resilience, may not be sufficient for ecological resilience (Green and Perrings 2013). Allocation by percentage accounts for changes in availability, but it may still lead to dewatering if, for example, a bilateral agreement allocates $50 \%$ of flow to each state and both states utilize their entire allotment for diversionary uses. Without protection for instream flows and the needs of aquatic ecosystems, collaborative institutions may degrade the environment. Moreover, a degraded environment will likely lead to future conflict as resources become increasingly scarce. Some institutions address this issue by complex allocation schemes that vary by flow level. The resilience of such schemes depends on the ability to agree on flow level, accuracy in modeling yield and variability, adjustments accounting for varied availability, and the amount of flow left unallocated (instream) (Kilgour and Dinar 2001).

\section{Extreme events provision}

Institutional and ecological resilience are defined as the capacity to cope with change (Yoffe et al. 2003), and yet transboundary water treaties regularly ignore the inevitability of extreme events. This is disturbing in light of recent research demonstrating that the intensity of state grievances is robustly correlated with the degree of flow variability in the basin, and that the presence of drought-adaptation provisions affects the intensity of complaints (Dinar et al. 2010). In addition, transboundary floods account for a disproportionate share of causalities and increased magnitude of loss (Bakker 2009).

Extreme fluctuations in flow can be addressed through an allocation mechanism, in separate provisions, or through single-issue treaties. Flood protection is commonly addressed in single-issue treaties, mostly as detailed agreements on joint infrastructure. Drought is rarely addressed in any detail. And, even when reduced water availability is addressed in the allocation scheme, ecosystem and biodiversity protections during drought are extremely rare (Giordano 2003).

\section{Joint monitoring and information exchange}

Continuous, systematic monitoring and data sharing are crucial for iterative governance of a dynamic resource (Garmestani et al. 2009, Cosens 2012). Monitoring is also an important aspect of water allocation and enforcement, and joint monitoring agreements can be the first cooperative step between states. In fact, joint monitoring correlates to fewer state grievances in water allocation and hydropower treaties (Dinar et al. 2010). When ecosystem knowledge is shared between parties, international resource managers can be responsive and flexible at the appropriate scale (Brown 2002), and can immediately focus resources on a problem rather than first negotiate over which data to use (Cosens 2003). To overcome tendencies to "hunker down" whereby states are less willing to share information when facing disturbance, the agreement to share data must be institutionalized through a treaty (Anderies et al. 2004, Putnam 2007).

Unfortunately, although many treaties include monitoring and data-sharing provisions, information sharing among states is relatively low (Grossman 2006). In many basins, monitoring inadequacy can be attributed to a lack of technological resources. Even where tributaries are frequently monitored and data is shared, incompatibility between datasets often hinders effective utilization of the data. Whatever the cause, weak data exchange impedes collaborative governance and exacerbates ecosystem harm from hydraulic infrastructure (Grossman 2006).

\section{Enforcement}

Enforcement reduces the intensity of complaints between states (Dinar et al. 2010) and can be structured either as imposition of punishment on defectors or as integrated benefit sharing, side payment, or issue linkage that so strongly incentivizes compliance that the agreement is self enforcing. Enforcement increases the likelihood of compliance, generally includes means for detecting noncompliance and thus providing transparency, and reduces the possibility of tying diplomatic actions against a noncompliant party to unrelated issues. Enforcement makes the agreement more robust and stable but must be coupled with monitoring to be effective (Keohane and Martin 1995). Self enforcement by way of benefit sharing occurs when multiple water-related goods are linked in the agreement such that defection by a party would lead to loss by that same party; thus, the benefits of defection are reduced and the incentives to cooperate are strengthened (Sadoff and Grey 2002, Wu and Whittington 2006).

\section{Dispute resolution mechanisms}

Previously agreed-upon methods of dispute resolution act as a failsafe against defection and provide states with a minimal incentive to cooperate. This mechanism also provides states with assurance that their concerns will be aired in an amicable environment. It also provides an additional means for adaptation in the face of uncertainty by providing a mechanism to resolve disputes over issues not anticipated during treaty negotiation (Cosens 2003). Dispute resolution mechanisms have been shown to reduce the intensity of state grievances (Dinar et al. 2010), but the degree of influence dispute resolution has over institutional and ecological resilience varies by basin and form. Disputes may be resolved by consultation, arbitration through neutral third party (e.g., International Court of Arbitration), diplomatic channels, or joint commission, among other means.

\section{Joint management}

In response to the diplomatic restraints of the negotiation process, states often establish joint commissions to manage shared waters. These agencies are typically composed of 
several technocrats from each state along with an equal number of representatives from each party and are directed to establish water management plans, develop collaborative projects, monitor water levels and use, resolve conflicts, gather and disseminate data, build local capacity, and engage the public, among other duties. Joint commissions charged with addressing multiple collective action problems, such as water allocation and environmental conservation, face complex obstacles to their effectiveness, but many argue that integration of all related problems is required for efficacy, especially in addressing feedback (Kliot et al. 2001, Dombrowsky 2007, Sadoff et al. 2008). Others argue that a singular focus on optimizing for a particular outcome fails to retain the full range of ecosystem services (Walker and Salt 2006, Zellmer and Gunderson 2009). If addressing multiple issues reduces the effectiveness of an organization but a singular focus leads to exacerbation of related problems, a balance must be struck whereby the most crucial related problems, such as sanitation and ecosystem resilience, are addressed alongside resource distribution (Schmeier 2010, Cosens and Stow 2013). After all, an organization that focuses solely on how to allocate water on the front end and has no jurisdiction to mitigate or even monitor withdrawals will only be effective until the river runs dry.

\section{Iterative processes for adaptive management}

There are no water treaties that explicitly spell out adaptive management principles; thus, the effect of these principles on institutional resilience cannot currently be calculated. However, the process of iterative governance is widely heralded as the most appropriate management technique for promoting ecological resilience (Cosens 2010, 2012, Eckstein 2010). As discussed above, the difficulty of negotiations tends to result in relatively brief documents that leave much of the operational tedium to be worked out by technocrats. Given the need for continuous learning and adaptation and the difficulty of renegotiation, mandating explicit management techniques (e.g., use $\mathrm{X}$ amount of water for $\mathrm{Y}$ purpose until $\mathrm{Z}$ occurs) in a treaty would not be the most effective method of instilling iterative processes into transboundary water management. Instead, we propose establishing a mechanism for collaboration at the basin scale that binds participants to govern collaboratively and iteratively (e.g., joint commission). Key principles for guiding the governance of that basin collaboration are discussed in the next section, followed by an in-depth analysis of one transboundary river basin organization that exemplifies the application of many of these principles.

\section{ADAPTIVE GOVERNANCE PRINCIPLES THAT FOSTER RESILIENT SOCIAL-ECOLOGICAL SYSTEMS}

Governance that recognizes linkages between social and ecological systems enhances resilience by utilizing the natural adaptive capabilities of the ecological system and the social system's ability to respond to ecological problems (Cosens 2010, 2012). First, to understand the relation between governance and adaptive management, we will rely on the following definition in which "governance is the process of resolving trade-offs and of providing a vision and direction for sustainability, management is the operationalization of this vision..." (Boyle et al. 2001). Adaptive governance requires integration of multiple levels of action-government, nongovernmental, and individual — and among agencies within the same level of government with overlapping authority (Folke et al. 2005). Adaptive governance moves from a focus on efficiency and optimization to a focus on jurisdictional diversity, redundancy, and multiple levels of management that include a role for local knowledge and local action (Cosens and Williams 2012, Cosens 2012).

Governance needed to foster ecosystem resilience requires flexibility to adapt but will be rejected by societies if it disregards the effect on the social system itself, thus local input is necessary. Delegation of increased flexibility for adaptive management from sovereign nations to international commissions must assure that increased flexibility is exercised in a legitimate manner that is responsive to the social system (Cosens 2012). The key is operating through a process that is accurately scaled, well informed, open to the public, influenced by local stakeholders, and adaptable to change (Cosens 2012). The following principles are necessary to account for scale and crucial to maintaining legitimacy: each level of control must communicate and coordinate, engage the public while building the public's capacity to participate, and have authority to act to address issues as they arise.

\section{Multiple, overlapping levels of control and horizontal and vertical flow of information and coordination}

Complex systems rarely have clearly identifiable scales for governance (Ruhl and Salzman 2010). Although coordination may be needed across an entire ecosystem, issues that arise do not always require action at such a large scale (Ruhl and Salzman 2010, Cosens et al. 2012). In response, resilience thinking rejects the call for a single, efficient level of management and instead calls for multiple overlapping authorities (Cosens 2010, Cosens 2012). This approach allows response across different scales depending on the source and impacts of the problem. Further, nested scales of management authority enable adaptation and innovation at smaller scales while providing large scale stability. In addition to including multiple levels of governance and nongovernmental local action, resilience thinking assures that coordination must at least occur at the scale of the social-ecological system involved but must include linkage to multiple scales of governance to allow adaptive response. These linkages among nested scales are of particular importance when there is a difference between the scale of the problem source and the scale of the required solution (Long 2009). Thus coordination 
of various levels of governance through basin-scale collaboration or a formal commission is essential for addressing problems that manifest at that scale (Long 2009).

Information sharing also is crucial to reducing uncertainty when problems occur, especially when caused at multiple scales and from diverse sources. In a system of nested jurisdiction, information must flow freely from the bottom, that is, those experiencing the problem firsthand, to the uppermost appropriate jurisdiction, that is, those holding the resources required to solve the problem or those that coordinate action and vice versa. This is especially true given that uncertainty, such as with the ecological response to climate change, can never be reduced to zero. Higher levels of governance must be informed by the facts on the ground. Instead of funneling information down, data must be shared up and down and across jurisdictions for a coordinated problem-solving approach (Cosens 2010).

\section{Meaningful public participation and local capacity building}

Accountability concerns may be addressed by procedural controls on the actors and citizen checks via public participation and local capacity building. Vertical and horizontal information sharing is incomplete if local knowledge does not enter the flow. Meaningful public participation refers to a two-way flow of information in which governmental agencies provide information from their own expertise, incorporate local knowledge, and empower a greater role for public input in decision making (McKinney and Harmon 2004). To be meaningful, public participation requires that the exchange of information and input occurs at a time and place convenient to local citizen volunteers. Gathering local input may involve attendance by agency personnel at regularly scheduled community meetings, rather than holding separate meetings (Cosens 2003). For a longterm, complex process, it may also require funding for the participation of local leaders who generally lack the resources to participate. Resources at the local level are required and, in many circumstances, capacity building can better prepare the local response to an ecological problem. Finally, meaningful public participation results in public input carrying enough weight to influence the final decision; adaptive governance requires more than a mere opportunity for public comment.

\section{Authority to respond to changed circumstances across a range of scenarios}

The final step in designing an adaptive structure of governance is to ensure that the actor at the appropriate scale, acting with information from all levels of jurisdiction, including an informed and active public, has authority to address whatever problem continuous monitoring reveals. Otherwise, the system is well informed but impotent. Ecological problems are typically of the "wicked" variety-where actors cannot agree on the definition of the problem, much less the solution
- and the uncertainty of any given response cannot be eliminated. Uncertainty cannot be an excuse for inaction but should instead be the catalyst for iterative action. When continuous system monitoring reveals an ecological problem, decision making and action should occur at the appropriate scale , which is not necessarily at the basin or international level, while accountability is maintained through a political or peer-selection process (Cosens 2010).

\section{THE OKAVANGO RIVER BASIN: RESILIENCE ELEMENTS APPLIED}

Globally, water-related conflict increases with water variability (Dinar et al. 2010). Arid and semi-arid basins experience significantly more intense conflict and relatively few cooperative events categorized as "slightly cooperative." Interestingly, arid regions are also more likely to engage in highly cooperative behavior, such as collaborative management and international agreement (i.e., treaties). Thus, just as conflict increases with extremes in water availability, high levels of cooperation are also more likely in basins that experience extreme climatic variability. Whether basin states conflict or cooperate in times of extremes depends on their institutional capacity to absorb the extreme event (Wolf et al. 2003). Shared by Angola, Botswana, and Namibia in southwestern Africa (see Fig. 1), the Okavango River Basin provides an interesting case study of the capacity of states to implement some of the components of adaptive governance and in particular to collaboratively manage a volatile and vital resource where uncertainty runs high.

Fig. 1. Map of the Okavango River Basin.

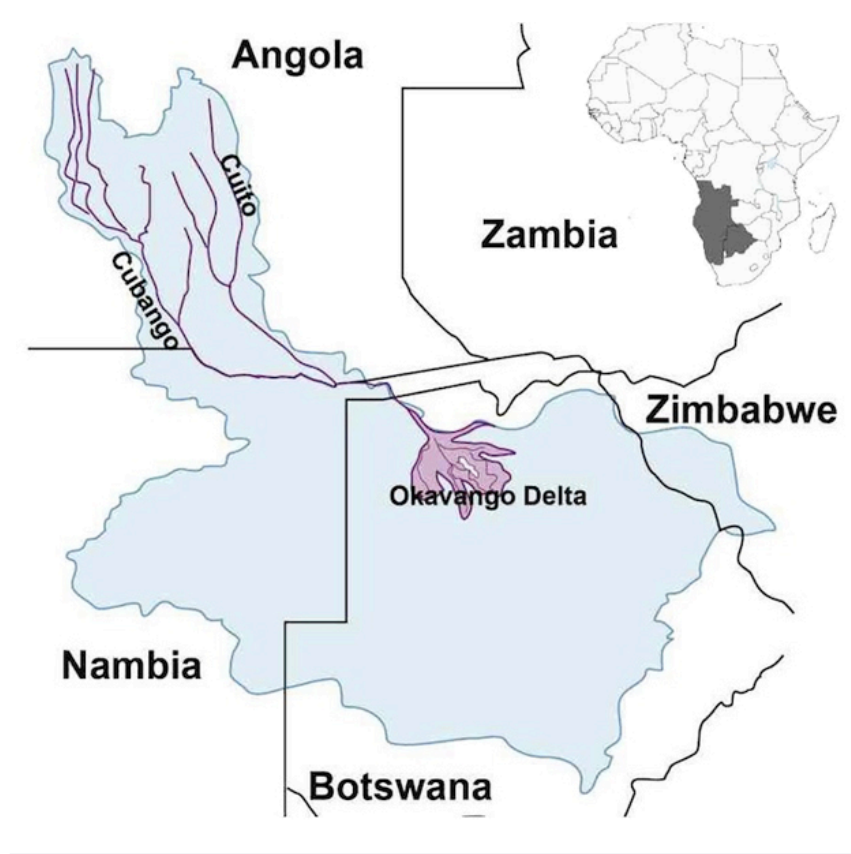


Table 1. Summary of elements.

A. Treaty mechanisms and their status in the Okavango treaties.

B. Adaptive governance principles and their status in the Okavango governance structure.

\begin{tabular}{lcl} 
A. Treaty Mechanisms & In treaty? & Status \\
\hline Water allocation method & No & Unresolved, ongoing preparation \\
Extreme events provision & Yes & Proactive planning approach, including authority to respond \\
Joint monitoring and information exchange & Yes & Ongoing and improving \\
Enforcement & No & Integrated approach but trade-offs yet to be delineated \\
Dispute resolution mechanism & Yes & OKACOM charged with conflict prevention and resolution; \\
& & consensus; negotiation \\
Joint management & Yes & OKACOM \\
Iterative processes for adaptive management & No & Not explicit in treaty but may be in governance framework
\end{tabular}

\begin{tabular}{lcl} 
B. Adaptive governance principles & $\begin{array}{c}\text { In governance } \\
\text { framework? }\end{array}$ & Status \\
\hline Overlapping levels of control & Yes & Stakeholders at multiple scales have input \\
Horizontal and vertical information flow & Yes & Robust data sharing \\
Meaningful public participation & Yes & Advanced participation methods \\
$\begin{array}{l}\text { Local capacity building } \\
\text { Authority to respond }\end{array}$ & Yes & Local contractors prioritized; collaboration with local stakeholders \\
\end{tabular}

The natural state of the Okavango is one of extremes, characterized by high water in the wet season and severe aridity in the dry season. Ninety-five percent of flow originates in the headwaters with environmentally dependent ecotourism economies downstream. Decades of civil war have impeded development and collaboration. Yet, the region experiences very little conflict over water; conflict did not even arise in the 1980s and 1990s during prolonged periods of severe drought when average flows shrank by $14-45 \%$ (McCarthy et al. 2000). With the aid of international donors, a robust riverbasin organization has emerged with a focus on ambitious data collection, collaborative governance, local empowerment, and environmental stewardship in a relatively pristine ecosystem (Mbaiwa 2004).

However, the institutional capacity of the Okavango, although strong, may face increased pressure if climate-change models predicting increased water variability play out. Quantitative studies indicate that increased water variability caused by global warming could challenge even resilient governance regimes (Dinar et al. 2010). After all, the "likelihood and intensity of conflict rises as the rate of change within the basin exceeds the institutional capacity to absorb that change" (Yoffe et al. 2004). Thus, the analysis below applies the two frameworks outlined in the previous sections-a framework for institutionally resilient treaties and a framework for adaptive governance-to assess the present and future capacities of the Okavango's riparian states to adapt to change (see summary in Table 1). This section is meant to provide examples of framework application, rather than providing a comprehensive analysis of the adaptive capacity of the basin.

\section{Hydrology of the Okavango River Basin}

The Okavango River Basin of southwest Africa provides vital water resources to an otherwise arid region. The basin is located in a transition zone between high and low rainfall areas and is fed by a single wet season, resulting in high flow variability between seasons-between $-45 \%$ and $+65 \%$ of mean annual flow (Ashton and Neal 2003). Annual floodwater drains into the Okavango Delta, which is the second-largest inland delta in the world. It is also an internationally recognized ecoregion, designated a Wetland of International Importance by the Ramsar Convention in 1996 and identified as a priority ecoregion by the World Wildlife Fund Global 200 project (Olson and Dinerstein 2002). The rich biodiversity of the area attracts ecotourism, a top economic driver in downstream Botswana (Kgathi et al. 2006). The Okavango is one of the least developed and largest basins in Africa, but the socioeconomic needs of the growing population are forecasted to spur increased development, especially for irrigation (Andersson et al. 2003, Hughes et al. 2011).

The few diversions from the Okavango serve domestic and relatively small irrigation needs. Supporting rich biodiversity and economic interests of the delta region, flow into the wetlands represents the largest water use in the basin (Ashton 2003). Angola, the farthest upstream riparian state, receives nearly four times the precipitation of the lowland southern states of Botswana and Namibia and contributes almost $95 \%$ 
of the annual delta inflow (Andersson et al. 2003, Ashton 2003). Decades of civil war in Angola prevented hydraulic development, and now that the nation enjoys peace, development pressures are expected to intensify (Hughes et al. 2011). For these reasons, international efforts have focused on increasing the local capacity and data-gathering systems in Angola.

The most likely development scenarios, which include construction of one hydropower dam, formal irrigation schemes, population growth, and deforestation, project limited impact on annual flow, but the models consider each element individually and not as a comprehensive development scheme. For example, potential formal irrigation schemes are projected to decrease annual flow by $2 \%$ and minimum monthly flow by $5 \%$, while deforestation would increase flow by $2.5 \%$ (Andersson et al. 2006, Murray-Hudson et al. 2006, Milzow et al. 2010).

Additionally, various climate change models project a longterm (2050-2080) decrease in annual mean water flow of $14 \%-20 \%$ and a change in the timing of peak discharge by one month, whereas other models estimate dramatically increased flow in the near future (2020-2050; Andersson et al. 2006). A review of many projections reveals a lack of consensus on the sign or magnitude of change, yet concludes that there is a high probability of large changes in water availability in the basin, and especially the delta (MurrayHudson et al. 2006, Hughes et al. 2011).

Given the uncertainty and variability of climate change models, the basin states should take a cautious and iterative approach to development (Ellery and McCarthy 1994, Andersson et al. 2003). The Basins at Risk project identified the basin as having the potential for conflict in the near future (Yoffe et al. 2003). To manage this pressure and facilitate sustainable development, the three riparian states and the international community have heavily invested in collaborative and integrated management of the basin through multiple international agreements and institutional and local capacity building projects (Mbaiwa 2004).

\section{Okavango treaties and agreements}

Several agreements lay out governance of the Okavango. First, the 1994 Agreement between the Governments of the Republic of Angola, the Republic of Botswana, and the Republic of Namibia on the Establishment of a Permanent Okavango River Basin Water Commission (OKACOM) established this body as a technical advisor to all three countries on issues relating to conservation, utilization, and development (OKACOM 1994). Thirteen years later, the Agreement Between the Governments of the Republic of Angola, the Republic of Botswana and the Republic of Namibia on the Organizational Structure of OKACOM came into force, which establishes three branches of OKACOM: the Secretariat for administrative and financial matters, the Steering Committee for technical advice, by way of three task forceshydrological, biodiversity, institutional; and the Commission itself which supervises and sets policy objectives (OKACOM 2007). For purposes of content analysis for particular treaty mechanisms, the entire record of 11 agreements signed over a span of 16 years is reviewed and discussed as a whole.

Article 4 of the 1994 treaty establishing OKACOM sets out its function as an advisor on issues such as:

1. Determining the long term safe yield of water

2. Reasonable levels of demand

3. Criteria for conservation, equitable allocation, and sustainable utilization

4. Investigations into development, either jointly or by individual states

5. Pollution prevention and aquatic weed control

6. Short-term drought measures (1994).

The agreement concerning the organizational structure of OKACOM elaborated on these functions, detailing OKACOM's duty to prepare a draft allocation agreement and technical, economic, financial, and legal information in support of a Master Plan for integrating water use in the basin. The Memorandum of Understanding for the Establishment of a Secretariat (OKASEC) for the Commission details secretarial functions relating to information sharing and communication to include development of an information strategy using existing sources of data and to provide institutional memory (OKACOM 2005).

\section{Water allocation method}

Instead of establishing an allocation regime by treaty, the 2006 agreement concerning the organizational structure of OKACOM charged the Commission with drafting the Agreement on Shared Water Resources of the Basin. The only guidance contained in a treaty is found in the original 1994 treaty that gave responsibility to OKACOM to prepare "equitable allocation" (1994). To date, no allocation scheme has been established as states are still in the preparation stage - evaluating demand and supply, structuring water laws, and forming councils (OKACOM 2010a).

Water needs in the basin have largely focused on population growth projections and current land-use patterns. Consumptive water needs are estimated at 23.2 million cubic meters annually for the entire basin, or about $0.23 \%$ of the annual flow into the delta (Ashton 2003). Projections of increased demand for the year 2020 range from $0.33 \%$ to $3.0 \%$ of mean annual flow. The worst-case scenario demand projections amount to only a $3.0 \%$ increase in water use, a sum that may seem insignificant considering the degree of natural variability in the basin. Likewise, many climate change scenarios do not exceed the standard deviation of historical 
flows (Hughes et al. 2011). Given the dramatic variability in the natural system, the Okavango displays high levels of resilience to flow variability (Hughes et al. 2011). However, sustained increases in use may pose unforeseeable consequences on the basin, especially on margins of the delta that no longer receive annual floodwaters (Murray-Hudson et al. 2006).

Environmental flow assessments have been conducted with various disciplinary focuses (e.g., geomorphology, socioeconomics, hydrology) as part of the Cubango-Okavango River Basin Transboundary Diagnostic Analysis (OKAKOM 2011). They conclude that the largest user of water comes from the environmental demands of the delta, and that development decisions must first consider environmental impacts of any project both upstream and downstream. At this time when development is low and environmental need is high, OKACOM should capitalize on the lack of competition over uses and allocate adequate environmental flow in the allocation scheme (Quesne et al. 2010).

Because the stability granted by a formal allocation scheme is likely to spur development, any agreement on allocations must consider the potential impacts with respect to decadal periods of low flow and minimal environmental flow (Hughes et al. 2011). Likewise, hydraulic development may impede critical sediment transport and reduce channel shifting that is critical to biodiversity and fertility (Kgathi et al. 2006). Coupled with climate change-induced reductions in precipitation, it is vital that basin states work collaboratively on development decisions and to continuously monitor the environmental impacts of water use.

\section{Extreme events}

Very familiar with extreme hydrological events, the states of the Okavango have taken a proactive approach to dealing with drought and flooding, most notably by developing an advance warning system. The 2010 Protocol on Hydrological Data Sharing for the Okavango River Basin states that: "The [Hydrological Task Force] shall provide OKASEC [the Secretariat] with the best available information on floods, droughts and pollution magnitudes at different time and space scales. OKASEC shall channel the information to decision making bodies and other public actors in the three member Countries" (OKACOM 2010b). Article 4.6 of the 1994 treaty addresses drought concerns by granting OKACOM authority to advise any state on measures to "alleviate short term difficulties resulting from water shortages...during periods of drought." When advising, OKACOM should consider stored water availability and the "water requirement" of each state (OKACOM 1994).

To better adapt to inevitable change, the states collaborate on the Transboundary Diagnostic Analysis to establish baseline flows, water-quality levels, etc. (OKACOM 2011). This analysis, along with Andersson et al. (2006), Hughes et al.
(2011), and others assessed the hydrology, climate, and social dynamics of the basin to run models of potential impacts of development, land-use change, and climate change. Although they were mostly inconclusive because of the difficulties of modeling multiple changes in a dynamic system, they were successful in identifying data-collection problems, most notably the lack of data in Angola where 95\% of flow originates.

\section{Monitoring}

Overall, hydrometric data in the region is sparse but improving (Kgathi et al. 2006, Hughes et al. 2011). A separate protocol exists for sharing hydrological data in the basin (OKACOM $2010 b$ ); the Steering Committee is charged with responsibility for the protocol, and the Hydrology Task Force implements the protocol. A short-term function of the Secretariat is to monitor and report quarterly on progress in implementing decisions, and a longer-term function is coordination of data collection and documentation. The Secretariat is charged with creating a plan of action for monitoring implementation of OKACOM agreements.

After each hydrological year, states have three months to provide a hydrological report to be distributed through the Secretariat, as per the 2010 protocol. Each state is responsible for its own hydrometerological monitoring stations which should monitor water level, water discharge, water quality, sediment transport, and meteorological data. Water-level measurements taken at key locations are to be recorded and shared daily. Water discharge and quality measurements are shared quarterly. Certain water-quality parameters are to be prioritized: electrical conductivity, total dissolved solids, dissolved oxygen, $\mathrm{pH}$, phosphates, nitrates, fecal coliforms, total hardness, temperature, turbidity, total suspended solids, and chlorophyll A. States share data with the Hydrological Task Force, and the Secretariat shares the data with decisionmaking bodies in the states. In addition, Article XIV binds each state to report data on floods, droughts, and pollution levels to the Hydrological Task Force to enable OKACOM to establish and operate the early warning information system. This level of monitoring detail is rare in international agreements and bodes well for the basin states' capacity to collaborate and adapt.

\section{Enforcement}

Traditional methods of enforcement, such as side payments, are not included in the collection of Okavango treaties. Instead, the parties have taken an integrated approach to managing the river basin. Issue integration functions as enforcement to the degree that defection, presumably for gain, on one issue correspondingly leads to loss on another. There are no delineated trade-offs because the issues are still in the assessment phase. However, OKACOM has taken strides to curb defection and corruption of process. For example, state representatives must disclose all potential conflicts of 
interests, and OKACOM is charged with approving accountability mechanisms and documentation (OKACOM 2006). Additionally, OKACOM may "institute any form of legal proceedings to protect the water resources of the Basin" (OKACOM 2006). This stick has yet to be tested or applied, so it is unclear if OKACOM might use this provision to initiate legal proceedings against a party whose action allegedly conflicts with OKACOM's conservation and protection mission.

Outside bodies and overlapping levels of governance play an enforcement role as well, especially donors. For example, the 2009 Agreement between Sweden and OKACOM on Support to the OKACOM Secretariat through the Swedish International Development Cooperation Agency (Sida) includes auditing clauses and entitles Sida to withhold disbursement of funds if OKACOM deviates from their plan. Additionally, OKACOM agreed to prevent corruption and take "rapid legal measures" to stop it and punish it (OKACOM 2004). Outside of direct contracts, external forces such as the Southern African Development Community (SADC) may exert enough influence to dissuade a party from defecting through measures like international sanctions or tense relations.

\section{Dispute resolution mechanism}

Article VII of the original 1994 treaty that established OKACOM vaguely provides that any disagreement "shall be settled by the Contracting Parties," but does not provide any detail about the process (OKACOM 2004). Later agreements spell out the decision-making process should the parties not reach consensus. OKACOM is charged with conflict prevention and resolution through consideration of any and all claims and complaints and instituting legal proceedings (OKACOM 2006). OKACOM has the liberty to define the process for dispute resolution (OKACOM 2006). If no consensus is reached after several attempts, "the matter shall be made the subject for negotiations between the parties" (OKACOM 2010c).

Additionally, the Secretariat is charged with "conflict prevention" (OKACOM 2005). The Secretariat may do this by monitoring activities in the basin and informing OKACOM of potential conflicts, dispute resolution if instructed by OKACOM, and serving as impartial broker in negotiations to reach consensus in OKACOM. All of these mechanisms are internal and not necessarily subject to neutral review, except that OKACOM is heavily partnered with international aid organizations that would likely withhold financial support should a conflict impede the mission of OKACOM. But the international pressure and related financial incentives are only temporary, and OKACOM will soon be financially independent. The inability to settle a dispute could impede adaptive decision making in the face of disturbance (Schmeier and Schulze 2012).

\section{Adaptive governance framework}

\section{Multiple, overlapping levels of governance}

At this seminal stage of developing a governance structure, actors at every level have input in the Okavango. International aid and development organizations, such as the United States Agency for International Development (USAID), World Wildlife Fund (WWF), and Sida, partner with regional players such as OKACOM and SADC, and many national agencies and nonprofits in each state, while strengthening avenues for local input.

Local scale. Considerable success has been made toward sustainable resource management by empowering local custodians. Local stakeholders have a voice in governing the Okavango through the Every River has its People Project, among other programs. The project gathers information from and facilitates information exchange among the many peoples of the Okavango. The aim is to empower local voices through educating OKACOM members about the problems facing local communities and developing joint solutions. In addition, local stakeholders take ownership of sustainable management through increased property rights. Through collective action, communities acquire conservancies or trusts to manage the resource. Additionally, the Basin Wide Forum consists of 10 local community representatives from each state and provides a forum for communication and knowledge exchange (ARD, Inc. 2009).

Nation scale. Each state provides constitutional protection for the environment and has a water ministry responsible for coordinating development. In Namibia, the Department of Water Affairs is charged with water resource management and coordinates the acts of other departments that may have an impact on water resources (Ashton and Neal 2003). Duties include monitoring, data sharing, and education. Thus, although multiple agencies may have authority over acts relating to water resources, one department acts as the stopgap custodian and coordinator of all water-related activities. Additionally, environmental flows must be accounted for in any water allocation scheme according to Namibian law. In Botswana, the Department of Water Affairs functions similarly to the Nambian counterpart by serving as a coordinating body for all water-related projects and custodian for water resources. In addition, Botswana has a regularly updated National Water Master Plan with which all projects that may impact or degrade water resources must comply. This results in a high level of collaboration among ministries and integrated national planning. Angola takes a decentralized approach to water governance by granting authority to provincial governments under the Water Law (Lei de Aqua, Law No. 6/02) and Water Sector Development Strategy (Ashton and Neal 2003).

Watershed scale. Most of this case study focuses on governance at the watershed scale through OKACOM, as the 
coordinator of authority over the Okavango. In addition to OKACOM's previously described governance innovations, a transboundary land-use plan is in preparation and will likely be adopted (ARD, Inc. 2009). OKACOM and partners have identified transboundary land-use planning as a priority to address often-conflicting land uses such as agriculture and wildlife tourism (i.e., migration interference) and completed a consultative land-use planning process (ARD, Inc. 2009).

Region scale. The SADC Revised Protocol on Shared Watercourses (2000), developed for the governance of basins in southern Africa, promotes collaboration between riparian states that protects sovereignty, the environment, and human rights. The Revised Protocol urges states to strike a sustainable balance between development of water resources for human needs and conservation and environmental enhancement. The Revised Protocol is not prescriptive and is generally a statement of guiding principles. As members, states pledge cooperation on socioeconomic, political, and security issues. All three Okavango riparian states are members of the SADC, but only Botswana and Namibia have ratified the Revised Protocol.

Other international aid organizations play a vital role in OKACOM's operations. The Integrated River Basin Management Project (IRBM), funded by USAID and SADC, developed OKACOM's institutional capacity by establishing the permanent Secretariat (OKASEC). Whereas IRBM took a demand-driven approach, the dependence of OKACOM on foreign aid both financially and operationally may signal a weakness in its authority to adapt. However, access to international expertise has also led to vast improvements in OKACOM, especially in terms of information flow, public participation, and local capacity building, and international aid is structured to decrease as OKACOM member states increase financial support (Ard, Inc. 2009).

\section{Horizontal and vertical flow of information}

The effort to increase data sharing is robust and ambitious in the Okavango Basin, especially considering the restraints of collecting historic data and the lack of monitoring stations. Through the IRBM project, great emphasis has been placed on increasing monitoring stations and building a metadatabase of all regional databases to be operated and maintained by the Secretariat. Beyond hydrometric data, IRBM's demand-driven approach to developing programs in the Okavango required international aid agencies to listen to the needs of OKACOM and local stakeholders. Strategic planning workshops were held early on to gather inputs, priorities, and recommendations from stakeholders. The demands of the stakeholders were then incorporated into project strategies and work plans.

A collaboration to increase information flow resulted in an inventory of available tools and an assessment of the need for new tools. Based on this, hydrometric monitoring stations were installed with a special emphasis on Angola where monitoring data was poor; a data hub called Sharing Water was established to identify and link various databases; training was provided to OKACOM on the use and maintenance of meta-databases; and guidelines were developed for uniform data collection, reporting, and monitoring methods. Likewise, the collaboration conducted environmental assessments of ecologically sensitive areas and recommended actions for the conservation of priority sites of significant biodiversity or areas that require better management to protect the watershed.

This data formed the basis of the Okavango Delta Management Plan (ODMP) and the Okavango Delta Information System (ODIS), which contain GIS data layers for land use, wildlife, demographics, etc. and is maintained by the Harry Oppenheimer Okavango Research Centre (HOORC) at the University of Botswana. The Every River has its People Project funded research on the basin, and the resulting data have also been cataloged at HOORC. Another project combines these data sources and other information being collected for the transboundary diagnostic assessment to prepare the framework for the Okavango Basin Information System (OBIS). One success of the Transboundary Diagnostic Analysis is the standardization of data collection to enable the compatibility of each state's datasets (Schmeier and Schulze 2012). Getting each basin state to communicate in the same technical language is the first step in establishing a flow of information.

Meaningful public participation and local capacity building Public participation in the Okavango is not limited to opportunities to comment on proposals drafted by authorities. OKACOM members and other key stakeholders have been trained in Advanced Participation Methods, a proven facilitation technique for rapid coordination of community action planning. These methods assist communities in developing collective visions and concrete action plans. Facilitators conduct workshops in communities to identify community project priorities, give the public a voice in describing current problems and success, assemble work teams, and prepare work plans to implement projects. The goal is to ensure public participation in all decisions and to distribute responsibility so that work teams take ownership of local projects.

To ensure that public participation is meaningful, OKACOM has put considerable effort into increasing the capacity of local communities to sustainably manage the resource. To support local partners and foster local capacity, OKACOM endorses a policy of procuring services from local contractors before looking for regional or international organizations. The IRBM project established community-based resource centers to demonstrate community-based water and natural resources management approaches, facilitate successful grant 
application through a community small grants program, and remove policy and regulatory barriers to community involvement. Local partners are encouraged to collaborate in project implementation, and the US Forest Service trained regional technical staff for vegetation and forest inventory, and Namibian foresters in fire management. The IRBM process provided additional training in water monitoring, data management, vegetation and mammal inventories, aerial survey design, facilitation of meetings, workshops, and community action programs, rapid appraisal techniques for conducting socioeconomic and biophysical assessments, grant and project proposal writing, NGO fiscal management, conservation agriculture, community-based conservation and tourism management, HIV/AIDS awareness, sanitation and public health, and strategic planning.

\section{Authority to adapt}

As mentioned previously, basin states are bound to gather and share data related to floods, drought, and pollution as per a particular protocol with OKACOM. In turn, the Hydrological Task Force shares the data with member states to facilitate early warning systems (OKACOM 2010b). Obviously, this system is key to adaptation because an institution must be aware of a changed circumstance before adapting to it. However, this is only a first step.

OKACOM's authority to adapt has not been tested since the end of the civil war in Angola, but great strides have been made to prepare for foreseeable challenges. Given that it is required to act by consensus, OKACOM's attempts at joint projects failed to move forward while war waged in Angola (Schmeier and Schulze 2012). Since peace has been established, successful joint projects have been carried out, largely with the aid of foreign agencies. Such projects have been proactive and focused on information gathering and sharing, local capacity building, integrated planning, etc.

An instance where the Commission faced environmental or social disturbance where adaptation was necessary has yet to play out. From the legal documents, OKACOM has the authority to take measures, such as the modification of water allocations, should the system experience a natural disturbance. The broad functional scope of OKACOM includes authority over basin-wide land-use planning, environmental conservation, joint development, and pollution prevention.

\section{CONCLUSION}

OKACOM is in a unique position for protecting the resources of the Okavango; there is relatively little development, so demand for consumptive use is low. This low level of competition among users gives OKACOM room to allocate flow for environmental purposes. Further, the largest use is already an environmental use, that is, flow into the delta to support biodiversity. Given this, reaching consensus on protecting that instream flow may not be an insurmountable challenge, considering that any development decisions must first consider environmental impacts upstream and downstream of any project per the Transboundary Diagnostic Analysis. At this time, when development is low and environmental need is high, OKACOM should capitalize on the lack of competition over uses, and ensure adequate environmental flow in the allocation scheme. Beyond ecological reasons, there are strong financial incentives to protect environmental flows as ecotourism booms in the delta. Ecotourism profit sharing between Botswana and upstream states may provide a self-enforcing incentive to protect instream flows and water quality upstream. Through economic integration, the states of the Okavango would have much to lose if they fail to protect their ecosystem, and large potential gains if the region maintains its pristine nature.

However, to ensure adaptive capacity, natural resource management must be broader than the river, especially considering the importance of sedimentation processes in feeding floodplains and the delta ecosystem (Soils and Simmonds 2009). Biodiversity must be protected as well, especially as development increases. Transboundary land-use planning, if done with species protection in mind, could be a good approach. In the planning process, managers should take heed of migration routes, habitat needs, and food-chain dynamics of all species. OKACOM is currently partnering with the Wilderness Wildlife Trust to conduct a baseline analysis of aquatic invertebrates in key sub-basins. A biomonitoring index was developed during past projects, and should be integrated into the robust monitoring protocol established by treaty, which already includes vegetation monitoring. OKACOM's Biodiversity Task Force plays a vital role in coordinating the objectives of water resource management with the demands of the broader ecosystem, but is in its seminal stage of program development, including the integration of transboundary fisheries management.

Overall, governance of the Okavango River Basin exhibits many important aspects of adaptability and collaboration (see summary in Table 1). OKACOM provides a concrete example of transboundary collaboration to promote ecological and social health. OKACOM's inclusivity and consensus model bode well for both the institutional and ecological resilience of the basin. With all riparian states on board, any development project must be approved by all states. Should Angola take steps to develop hydropower upstream, or Namibia move forward with a pipeline project to export water to drier areas, Botswana could force consideration of downstream environmental consequences before approving such projects. By addressing potential environmental consequences in advance, mitigation or compensation measures may be added to the project, and conflict potential is reduced. Consensus, in the short term, may lead to conflict while the states negotiate terms of a project, but in the long term, absence of approval 
of a detrimental upstream project would lead to greater conflict. Although many challenges still face this relatively young organization, by committing to a data-driven approach to decision making that emphasizes community ownership and empowerment, OKACOM has taken great strides in protecting and promoting long-term sustainable water resources and biodiversity.

The recent discovery of the Ohangwena II aquifer will likely alter the hydropolitical landscape of the region and provide a first test of the governance framework. The transboundary aquifer spans between Namibia and Angola and is projected to supply enough water to meet the demands of Namibia for hundreds of years, thus reducing upstream pressure on the delta (MacDonald et al. 2012). However, those projections are based on current levels of demand, and demand will likely increase with discovery of a relatively cheap resource (i.e., pressure reduces pumping cost), especially for irrigation. Increased agricultural production may have impacts that are detrimental to water quality and biodiversity in the delta, thus increasing the need for integrated, collaborative development. Regional governments should capitalize on their experience and relative success with the Okavango treaties to draft equally comprehensive agreements over the Ohangwena II aquifer.

The legal and governance frameworks described in this article aim to overcome the dilemma posed by the intersection of law and environmental science by providing guidance for the design of legal instruments and the implementation of adaptive governance for sound environmental management. Treaties with mechanisms for adaptive flow allocation, extreme events, information exchange, collaborative governance, and dispute resolution have been shown to increase the institutional capacity of basin states to absorb change. Likewise, governance elements such as overlapping levels of control, multi-directional information flow, meaningful public participation, local capacity building, and authority to respond may increase the adaptive capacity to manage a variable system. OKACOM is not a perfect example of each element, but perfection in governance does not exist, hence the need for iterative processes and adaptive capacity in natural resource management.

Responses to this article can be read online at: http://www.ecologyandsociety.org/issues/responses. php/5453

\section{Acknowledgments:}

This research was conducted with the support of an appointment to the Research Participation Program at the National Risk Management Research Laboratory administered by the Oak Ridge Institute for Science and Education. The views expressed in this paper are those of the authors and do not necessarily represent the views or policies of the U.S. Environmental Protection Agency.

\section{LITERATURE CITED}

Adger, W. N., K. Brown, D. R. Nelson, F. Berkes, H. Eakin, C. Folke, K. Galvin, L. Gunderson, M. Goulden, K. O'Brien, J. Ruitenbeek, and E. L. Tompkins. 2011. Resilience implications of policy responses to climate change. Wiley Interdisciplinary Reviews: Climate Change 2:757-766.

Anderies, J. M. 2006. Robustness, institutions, and large-scale change in social-ecological systems: the Hohokam of the Phoenix Basin. Journal of Institutional Economics 2:133-155. http://dx.doi.org/10.1017/S1744137406000312

Anderies, J. M., M. A. Janssen, and E. Ostrom. 2004. A framework to analyze the robustness of social-ecological systems from an institutional perspective. Ecology and Society 9(1): 18. [online] URL: http://www.ecologyandsociety.org/ vol9/iss $1 / \operatorname{art18/}$

Andersson, L., T. Gumbricht, D. Hughes, D. Kniveton, S. Ringrose, H. Savenije, M. Todd, J. Wilk, and P. Wolski. 2003. Water flow dynamics in the Okavango River Basin and Delta - a prerequisite for the ecosystems of the Delta. Physics and Chemistry of the Earth, Parts A/B/C 28(20-27):1165-1172.

Andersson, L., J. Wilk, M. C. Todd, D. A. Hughes, A. Earle, D. Kniveton, R. Layberry, and H. H. G. Savenije. 2006. Impact of climate change and development scenarios on flow patterns in the Okavango River. Journal of Hydrology 331(1-2):4357. http://dx.doi.org/10.1016/j.jhydrol.2006.04.039

ARD, Inc. 2009. Okavango Integrated River Basin Management Project (IBRM): final report. Prepared for OKACOM, the Directorate for Infrastructure and Services, Water Division of the SADC Secretariat, and United States Agency for International Development (USAID). ARD Inc., Burlington, Vermont, USA.

Ashton, P. 2003. The search for an equitable basis for water sharing in the Okavango River basin. Page 167 in M. Nakayama, editor. International waters in southern Africa. United Nations University Press, Tokyo, Japan.

Ashton, P., and M. Neal. 2003. An overview of key strategic issues in the Okavango basin. Pages 31-63 in A. R. Turton, P. J. Ashton, and T. E. Cloete, editors. Transboundary rivers, sovereignty and development: hydropolitical drivers in the Okavango river basin. Green Cross International, Geneva, Switzerland.

Bakker, M. 2009. Transboundary river floods: examining countries, international river basins and continents. Water Policy 11:269-288. http://dx.doi.org/10.2166/wp.2009.041 
Benson, M. H., and A. S. Garmestani. 2011. Embracing panarchy, building resilience and integrating adaptive management through a rebirth of the National Environmental Policy Act. Journal of Environmental Management 92:14201427. http://dx.doi.org/10.1016/j.jenvman.2010.10.011

Boyle, M., K. J., and B. Pond. 2001. Monitoring in support of policy: an adaptive ecosystem approach. Pages 116-137 in T. Munn, editor. Encyclopedia of global environmental change. Wiley, London, UK.

Brown, K. 2002. Innovations for conservation and development. Geographical Journal 168:6-17. http://dx.doi. org/10.1111/1475-4959.00034

Cash, D. W., W. Adger, F. Berkes, P. Garden, L. Lebel, P. Olsson, L. Pritchard, and O. Young. 2006. Scale and crossscale dynamics: governance and information in a multilevel world. Ecology and Society 11(2): 8. [online] URL: http:// www.ecologyandsociety.org/vol11/iss2/art8/

Cosens, B. 2003. Water dispute resolution in the west: process elements for the modern era in basin-wide problem solving. Environmental Law 33:949.

Cosens, B. 2010. Transboundary river governance in the face of uncertainty: resilience theory and the Columbia River Treaty. Journal of Land, Resources and Environmental Law 30:229-265.

Cosens, B. A., and M. K. Williams. 2012. Resilience and water governance: adaptive governance in the Columbia River Basin. Ecology and Society 17(4): 3. http://dx.doi. org/10.5751/ES-04986-170403

Cosens, B. 2012. Resilience and law as a theoretical backdrop for natural resource management: flood management in the Columbia River Basin. Environmental Law 42:241.

Cosens, B. 2013. Legitimacy, adaptation and resilience in ecosystem management. Ecology and Society 18(1): 3. http:// dx.doi.org/10.5751/ES-05093-180103

Cosens, B., A. Fremier, and J. Boll. 2012. Adaptive governance and resilience: the Columbia River Basin. When winter changes: hydrological, ecological, and biogeochemical responses. $45^{\text {th }}$ Annual Meeting of the American Geophysical Union. San Francisco, California, USA.

Cosens, B., and C. Stow. 2013. Resilience and water governance: addressing fragmentation and uncertainty in water allocation and water quality law. In R. Allen and A. S. Garmestani, editors. Social-Ecological Resilience and Law. Columbia University Press, New York, New York, USA.

Dinar, S., O. Odom, A. McNally, B. Blankespoor, and P. Kurukulasuriya. 2010. Climate change and state grievances: the water resiliency of international river treaties to increased water variability. Insights 3(22): 1-32.
Dombrowsky, I. 2007. Conflict, cooperation, and institutions in international water management: an economic analysis. Edward Elgar, Cheltenham, UK.

Eckstein, G. 2010. Water scarcity, conflict, and security in a climate change world: challenges and opportunities for international law and policy. Wisconsin International Law Journal 27:409-461.

Ellery, W. N., and T. S. McCarthy. 1994. Principles for the sustainable utilization of the Okavango Delta ecosystem, Botswana. Biological Conservation 70:159-168. http://dx. doi.org/10.1016/0006-3207(94)90284-4

Folke, C., T. Hahn, P. Olsson, and J. Norberg. 2005. Adaptive governance of social-ecological systems. Annual Review of Environmental Resources 30:441-473. http://dx.doi.org/10.1146/ annurev.energy.30.050504.144511

Garmestani, A. S., C. R. Allen, and H. Cabezas. 2009. Panarchy, adaptive management and governance: policy options for building resilience. Nebraska Law Review 87:1036-1054.

Giordano, M. 2003. Managing the quality of international rivers: global principles and basin practice. Natural Resources Journal 43(1):111-136.

Giordano, M. A., and A. T. Wolf. 2003. Sharing waters: postRio international water management. Natural Resources Forum 27:163-171. http://dx.doi.org/10.1111/1477-8947.00051

Green, O. O., and C. Perrings. 2013. Institutionalized cooperation and resilience in international water law. In C. Allen and A. Garmestani, editors. Social-Ecological Resilience and Law. Columbia University Press, New York, New York, USA.

Grossman, M. 2006. Cooperation on Africa's international water bodies: information needs and the role of informationsharing. Pages 173-235 in W. Scheumann and S. Neubert, editors. Transboundary water management in Africachallenges for development cooperation. German Development Institute, Bonn, Germany.

Hamner, J. H., and A. T. Wolf. 1998. Patterns in international water resource treaties: the transboundary freshwater dispute database. Colorado Journal of International Environmental Law and Policy 9.

Holling, C. S. 1978. Adaptive environmental assessment and management. Wiley, Chichester, UK.

Hughes, D. A., D. G. Kingston, and M. C. Todd. 2011. Uncertainty in water resources availability in the Okavango River basin as a result of climate change. Hydrology and Earth System Sciences 15:931-941. http://dx.doi.org/10.5194/ hess-15-931-2011 
Keohane, R., and L. Martin. 1995. The promise of institutionalist theory. International Security 20:39-51. http:// dx.doi.org/10.2307/2539214

Kgathi, D. L., D. Kniveton, S. Ringrose, A. R. Turton, C. H. M. Vanderpost, J. Lundqvist, and M. Seely. 2006. The Okavango; a river supporting its people, environment and economic development. Journal of Hydrology 331:3-17. http://dx.doi.org/10.1016/j.jhydrol.2006.04.048

Kilgour, D. M., and A. Dinar. 2001. Flexible water sharing within an international river basin. Environmental and Resource Economics 18:43-60. http://dx.doi.org/10.1023/ A:1011100130736

Kliot, N., D. Shmueli, and U. Shamir. 2001. Institutions for management of transboundary water resources: their nature, characteristics and shortcomings. Water Policy 3:229-255. http://dx.doi.org/10.1016/S1366-7017(01)00008-3

Long, J. 2009. From warranted to valuable belief: local government, climate change, and giving up the pickup to save Bangladesh. Natural Resources Journal 49:743.

Mbaiwa, J. E. 2004. Causes and possible solutions to water resource conflicts in the Okavango River Basin: the case of Angola, Namibia and Botswana. Physics and Chemistry of the Earth 29:1319-1326. http://dx.doi.org/10.1016/j.pce.2004.09.015

MacDonald, A. M., H. C. Bonsor, B. E. O. Dochartaigh, and R. G. Taylor. 2012. Quantitative maps of groundwater resources in Africa. Environmental Research Letters 7:024009. http://dx.doi.org/10.1088/1748-9326/7/2/024009

McCarthy, J., O. F. Canziani, N. A. Leary, D. J. Dokken, and K. S. White, editors. 2001. Climate change 2011: impacts, adaptation, and vulnerability. Cambridge University Press, Cambridge, UK. http://dx.doi.org/10.1029/2010GL042845

McCarthy, T. S., G. R. J. Cooper, P. D. Tyson, and W. N. Ellery. 2000. Seasonal flooding in the Okavango Delta, Botswana: recent history and future prospects. South African Journal of Science 96:25-33.

McKinney, W., and W. Harmon. The western confluence: a guide to governing natural resources. Island Press, Washington, D.c., USA.

Milzow, C., V. Burg, and W. Kinzelbach. 2010. Estimating future ecoregion distributions within the Okavango Delta wetlands based on hydrological simulations and future climate and development scenarios. Journal of Hydrology 381:89100. http://dx.doi.org/10.1016/j.jhydrol.2009.11.028

Murray-Hudson, M., P. Wolski, and S. Ringrose. 2006. Scenarios of the impact of local and upstream changes in climate and water use on hydro-ecology in the Okavango Delta, Botswana. Journal of Hydrology 331:73-84. http://dx. doi.org/10.1016/j.jhydrol.2006.04.041
Odom, O., and A. T. Wolf. 2011. Institutional resilience and climate variability in international water treaties: the Jordan River Basin as "proof-of-concept." Hydrological Sciences Journal 56:703-710. http://dx.doi.org/10.1080/02626667.20$\underline{11.574138}$

Oregon State University. Transboundary freshwater dispute database. Program in Water Conflict Management and Transformation, Institute for Watersheds, Oregon State University, Corvallis, Oregon, USA. [online] URL: http:// www.transboundarywaters.orst.edu/database/

Ostrom, E., M. A. Janssen, and J. M. Anderies. 2007. Going beyond panaceas. Proceedings of the National Academy of Sciences of the United States of America 104(39)1517615178. [online] URL: http://www.pnas.org/content/104/39/15176. full

Permanent Okavango River Basin Water Commission (OKACOM). 1994. Agreement between the governments of the Republic of Angola, the Republic of Botswana and the Republic of Namibia on the establishment of a Permanent Okavango River Basin Water Commission (OKACOM). OKACOM, Gaborone, Botswana.

Permanent Okavango River Basin Water Commission (OKACOM). 2005. Permanent Okavango River Basin Water Commission (OKACOM) Memorandum of Understanding for the establishment of a Secretariat (OKASEC) for the Commission. OKACOM, Maun, Botswana

Permanent Okavango River Basin Water Commission (OKACOM). 2006. The organizational structure for the Permanent Okavango River Basin Water Commission. OKACOM, Maun, Botswana.

Permanent Okavango River Basin Water Commission (OKACOM). 2007. Agreement between the Governments of the Republic of Angola, the Republic of Botswana and the Republic of Namibia on the organizational structure of OKACOM. OKACOM, Maun, Botswana.

Permanent Okavango River Basin Water Commission (OKACOM). 2010a. The Permanent Okavango River Basin Water Commission annual report 2010. OKACOM, Maun, Botswana.

Permanent Okavango River Basin Water Commission (OKACOM). 2010b. OKACOM Protocol on hydrological data sharing for the Okavango River Basin. OKACOM, Gabarone, Botswana.

Permanent Okavango River Basin Water Commission (OKACOM). 2010c. Rules and procedures of the Permanent Okavango River Basin Water Commission. OKACOM, Maun, Botswana.

Permanent Okavango River Basin Water Commission (OKACOM). 2011. Cubango-Okavango River Basin 
Transboundary Diagnostic Analysis. OKACOM, Maun, Botswana.

Putnam, R. D. 2007. E pluribus unum: diversity and community in the twenty-first century. The 2006 Johan Skytte Prize Lecture. Scandinavian Political Studies 30:137-174. http://dx.doi.org/10.1111/j.1467-9477.2007.00176.x

Quesne, T. L., J. H. Matthews, C. V. d. Heyden, A. J. Wickel, R. Wilby, J. Hartmann, G. Pegram, E. Kistin, G. Blate, G. K. d. Freitas, E. Levine, C. Guthrie, and C. McSweeney. 2010. Flowing forward: freshwater ecosystem adaptation to climate change in water resources management and biodiversity conservation. The World Bank, Washington, DC, USA.

Ruhl, J. B., and J. Salzman. 2010. Climate change, dead zones, and massive problems in the administrative state: guidleines for whittling away. California Law Review 98:59-120.

Sadoff, C., T. Greiber, M. Smith, and G. Bergkamp. 2008. Share: managing water across boundaries. International Union for the Conservation of Nature (IUCN), Gland, Switzerland. http://dx.doi.org/10.2305/IUCN.CH.2008.WANI.5. en

Sadoff, C. W., and D. Grey. 2002. Beyond the river: the benefits of cooperation on international rivers. Water Policy 15:119-131.

Schmeier, S. 2010. Navigating cooperation beyond the absence of conflict: mapping determinants for the effectiveness of river basin organizations. International Journal for Sustainable Societies, Special Issue: Water Wars in the 21st Century. 4(1-2):11-27

Schmeier, S., and S. Schulze. 2012. Governing environmental change in international river basins: the role of river basin organizations. International Journal of River Basin Management 1-16. http://dx.doi.org/10.2139/ssrn.1690244

Soils, C. C. and E. B. Simmonds. 2009. Okavango River Basin: transboundary diagnostic analysis project: environmental flow assessment module specialist report. Country: Namibia; discipline: geomorphology. OKACOM, Environmental Protection and Sustainable Management of the Okavango River Basin (EPSMO) Project, Global Environment Facility, Washington, D.C., USA.

Walker, B., and D. Salt. 2006. Resilience thinking: sustaining ecosystems and people in a changing world. Island Press, Washington, DC, USA.

Wolf, A. T., K. Stahl, and M. F. Macomber. 2003. Conflict and cooperation within international river basins: the importance of institutional capacity. Water Resources Update 125:31-40.

$\mathrm{Wu}, \mathrm{X}$., and D. Whittington. 2006. Incentive compatibility and conflict resolution in international river basins: a case study of the Nile Basin. Water Resources Research 42:15. http://dx.doi.org/10.1029/2005WR004238

Yoffe, S., G. Fiske, M. Giordano, M. Giordano, K. Larson, K. Stahl, and A. T. Wolf. 2004. Geography of international water conflict and cooperation: data sets and applications. Water Resources Research 40(5). http://dx.doi.org/10.1029/2003WR002530

Yoffe, S., A. T. Wolf, and M. Giordano. 2003. Conflict and cooperation over international freshwater resources: indicators of basins at risk. Journal of the American Water Resources Association 39:1109-1126. http://dx.doi.org/10.1111/ j.1752-1688.2003.tb03696.x

Zellmer, S., and L. Gunderson. 2009. Why resilience may not always be a good thing: lessons in ecosystem restoration from Glen Canyon and the Everglades. Nebraska Law Review 87:894-923. 